\title{
Long term visual outcome of radiated uveal melanomas in eyes eligible for randomisation to enucleation versus brachytherapy
}

\author{
Devron H Char, Stew Kroll, Jeanne M Quivey, Joseph Castro
}

\begin{abstract}
Aims-To determine the long term visual outcome of patients who were eligible for randomisation to enucleation versus brachytherapy in a US collaborative ocular melanoma study (COMS) but were treated with either helium ion or ${ }^{125}$ I radioactive plaque therapy.

Method-A retrospective analysis was performed of 426 ciliochoroidal melanomas that met COMS inclusion criteria for randomisation to enucleation versus radioactive plaque but were treated with either helium ions or ${ }^{125}$ I brachytherapy. Results-At 3 years $36.0 \%$ of eyes had $6 / 12$ or better visual acuity. The length of visual retention was most dependent on tumour thickness, tumour location with respect to the optic nerve, fovea, or ciliary body, and patient age. In addition to these factors, the retention of $6 / 12$ visual acuity and the time to $6 / 120$ visual acuity were dependent on the preoperative visual acuity. The risk of visual loss was greatest immediately after treatment and decreased with time. The 5 year actuarial metastatic rate was approximately $13 \%$. Patients at the greatest risk of post-radiation visual loss had significantly greater risk of tumour related mortality.

Conclusions-Some patients who would have been eligible for randomisation to either enucleation or radioactive plaque therapy can be irradiated with retention of excellent vision.
\end{abstract}

(Br F Ophthalmol 1996; 80: 117-124)

The optimum management of uveal melanoma is uncertain. A number of retrospective studies have shown no evidence that the type of ocular therapy, either locally effective radiation or enucleation, has a definitive survival advantage. ${ }^{1-6}$ In September 1985 the Collaborative Ocular Melanoma Study (COMS) was initiated to evaluate the effect of brachytherapy versus enucleation on survival in some patients with uveal melanoma. ${ }^{7}$ The incidence of metastatic deaths in patients eligible for entry into that trial, who were treated more than 5 years ago and had $100 \%$ follow up after helium ion radiation, was approximately $10 \% .{ }^{8}$ The absence of a demonstrable survival advantage with enucleation and doubts about the potential of a study with a low metastatic death rate to demonstrate a significant treatment effect led many American ocular oncologists not to participate in the above trial. ${ }^{9}$
Obvious advantages of retaining an eye include cosmesis and function. In both prospective and retrospective analyses of irradiated uveal melanoma patients, factors shown to correlate with visual outcome include tumour thickness, tumour location, pretreatment visual acuity, age, and type of radiation. ${ }^{4810-12}$ As an example, 5 years after helium ion radiation approximately $60 \%$ of patients with tumours $<6 \mathrm{~mm}$ thick that were $>3 \mathrm{~mm}$ from the nerve or fovea had $\geqslant 6 / 15$ vision. ${ }^{8}$ In contrast, less than one quarter of patients with either thicker tumours, those melanomas $<3 \mathrm{~mm}$ from the nerve or fovea, or both, retained that level of vision. In this study, we reviewed retrospectively uveal melanoma patients we irradiated who would have been eligible for entry into the COMS trial of enucleation versus brachytherapy to determine their long term visual outcomes and to assess the relative importance of tumour and patient factors on post-radiation visual retention. We also compared metastatic rates of individuals as a function of their pretreatment risk of visual loss.

\section{Materials and methods}

We reviewed retrospectively the records of the 718 patients with irradiated uveal melanoma treated between 1978 and 1993. We selected all cases that met the entrance criteria for the COMS trial comparing enucleation with radiation. ${ }^{7}$ Briefly, the major ocular entrance criteria involved tumour size and tumour location. Uveal melanomas had to be no greater than $16 \mathrm{~mm}$ in diameter and between 2.5 to $8 \mathrm{~mm}$ in height. More recently, the size criterion has been modified to include patients with tumours up to $10 \mathrm{~mm}$ in height. Location restrictions were that tumours could not be contiguous to the optic disc. If they were within $2 \mathrm{~mm}$ of the disc and involved less than 3 clock hours, they could be entered at the discretion of the surgeon. Tumours were excluded if the majority of the tumour involved the ciliary body or if the iris-corneal angle was involved. When these criteria were applied to our database, 221 tumours were excluded because of tumour size and/or tumour location criteria (Table 1). An additional 29 tumours were excluded because of previous therapy, and six were excluded because they lacked adequate post-treatment visual acuity data.

The emphasis of our investigation was visual outcome, so we analysed our data with and without some patients who did not meet the non-ocular COMS criteria. The majority of these latter exclusion criteria involved either 
Table 1 Sample exclusions to match COMS eligibility criteria

\begin{tabular}{|c|c|c|c|}
\hline & Helium ion & I-125 plaque & Total \\
\hline $\begin{array}{l}\text { Treated before } 1994 \\
\text { Primary exclusions }\end{array}$ & 347 & 371 & 718 \\
\hline No follow up & 1 & 5 & 6 \\
\hline Previous therapy & 9 & 20 & 29 \\
\hline Posterior location & 51 & 71 & 122 \\
\hline Anterior location & 13 & 9 & 22 \\
\hline Size & 62 & 15 & 77 \\
\hline Totals & 136 & 120 & 256 \\
\hline \multicolumn{4}{|l|}{ Other exclusions } \\
\hline Age under 21 & 1 & 1 & 2 \\
\hline Other malignancies & 10 & 16 & 26 \\
\hline $\begin{array}{l}\text { Poor visual acuity in } \\
\text { contralateral eye }\end{array}$ & 4 & 4 & 8 \\
\hline Totals & 15 & 21 & 36 \\
\hline Eligibility for study & 196 & 230 & 426 \\
\hline
\end{tabular}

ability to obtain follow up or exclusions because of increased risk of non-melanoma related death. Although these cases did not alter our results, to match COMS eligibility best, we excluded 36 patients because of age, poor visual acuity in the contralateral eye, or the presence of earlier primary or metastatic malignancies (Table 1). Overall, 426 patients met entrance criteria.

Table 2 Patient and tumour summary statistics for 426 eligible cases

\begin{tabular}{|c|c|c|c|c|c|c|}
\hline \multirow[b]{2}{*}{ Variable } & \multicolumn{2}{|l|}{ Total } & \multicolumn{2}{|l|}{ Helium ion } & \multicolumn{2}{|c|}{ I-125 plaque } \\
\hline & $(n=426)$ & $\%$ & $(n=196)$ & $\%$ & $(n=230)$ & $\%$ \\
\hline \multicolumn{7}{|l|}{ Sex: } \\
\hline F & 184 & $43 \cdot 2$ & 90 & $45 \cdot 9$ & 94 & $40 \cdot 9$ \\
\hline \multicolumn{7}{|l|}{ Age (years): } \\
\hline 21 to $<40$ & 58 & $13 \cdot 6$ & 29 & $14 \cdot 8$ & 29 & $12 \cdot 6$ \\
\hline$>40$ to $<50$ & 74 & $17 \cdot 4$ & 35 & $17 \cdot 9$ & 39 & $17 \cdot 0$ \\
\hline$>50$ to $<60$ & 89 & $20 \cdot 9$ & 44 & $22 \cdot 4$ & 45 & $19 \cdot 6$ \\
\hline$>60$ to $<70$ & 126 & $29 \cdot 6$ & 59 & $30 \cdot 1$ & 67 & 29.1 \\
\hline$>70$ & 79 & $18 \cdot 5$ & 29 & $14 \cdot 8$ & 50 & $21 \cdot 7$ \\
\hline \multicolumn{7}{|l|}{ Largest basal diameter (mm): } \\
\hline$<8$ & 81 & $19 \cdot 0$ & 39 & $19 \cdot 9$ & 42 & $18 \cdot 3$ \\
\hline$>8$ to $<10$ & 82 & $19 \cdot 2$ & 38 & $19 \cdot 4$ & 44 & $19 \cdot 1$ \\
\hline$>10$ to $<12$ & 152 & $35 \cdot \overline{7}$ & 67 & $34 \cdot 2$ & 85 & $37 \cdot 0$ \\
\hline$>12$ to $<14$ & 68 & $16 \cdot 0$ & 36 & $18 \cdot 4$ & 32 & 13.9 \\
\hline$>14$ to $<16$ & 43 & $10 \cdot 1$ & 16 & $8 \cdot 2$ & 27 & $11 \cdot 7$ \\
\hline \multicolumn{7}{|l|}{ Ultrasound height (mm): } \\
\hline$<4$ & 110 & $25 \cdot 8$ & 44 & $22 \cdot 4$ & 66 & $28 \cdot 7$ \\
\hline$>4$ to $<5$ & 89 & $20 \cdot 9$ & 37 & 18.9 & 52 & $22 \cdot 6$ \\
\hline$>5$ to $<6$ & 73 & $17 \cdot 1$ & 34 & $17 \cdot 3$ & 39 & $17 \cdot 0$ \\
\hline$>6$ to $<8$ & 97 & $22 \cdot 8$ & 44 & $22 \cdot 4$ & 53 & $23 \cdot 0$ \\
\hline$>8$ to $<10$ & 57 & $13 \cdot 4$ & 37 & $18 \cdot 9$ & 20 & $8 \cdot 7$ \\
\hline \multicolumn{7}{|l|}{ Degree of retinal detachment: } \\
\hline None & 141 & $33 \cdot 1$ & 64 & $32 \cdot 7$ & 77 & $33 \cdot 5$ \\
\hline$<1 / 8$ fundus & 117 & $27 \cdot 5$ & 60 & $30 \cdot 6$ & 57 & $24 \cdot 8$ \\
\hline$>1 / 8$ to $<3 / 8$ fundus & 84 & $19 \cdot 7$ & 30 & $15 \cdot 3$ & 54 & $23 \cdot 5$ \\
\hline$>3 / 8$ fundus & 84 & $19 \cdot 7$ & 42 & $21 \cdot 4$ & 42 & $18 \cdot 3$ \\
\hline \multicolumn{7}{|c|}{ Minimum distance to nerve or fovea (mm): } \\
\hline 0 to $<2$ & 166 & $39 \cdot 0$ & 71 & $36 \cdot 2$ & 95 & $41 \cdot 3$ \\
\hline$>2$ to $<4$ & 78 & $18 \cdot 3$ & 32 & $16 \cdot 3$ & 46 & $20 \cdot 0$ \\
\hline$>4$ to $<6$ & 102 & 23.9 & 51 & $26 \cdot 0$ & 51 & $22 \cdot 2$ \\
\hline$>6$ & 80 & $18 \cdot 8$ & 42 & $21 \cdot 4$ & 38 & $16 \cdot 5$ \\
\hline \multicolumn{7}{|c|}{ Location of anterior tumour margin: } \\
\hline Posterior to equator & 231 & $54 \cdot 2$ & 97 & $49 \cdot 5$ & 134 & $58 \cdot 3$ \\
\hline Choroid anterior to equator & 151 & $35 \cdot 4$ & 72 & $36 \cdot 7$ & 79 & $34 \cdot 3$ \\
\hline Ciliary body & 44 & $10 \cdot 3$ & 27 & $13 \cdot 8$ & 17 & $\mathbf{7 \cdot 4}$ \\
\hline \multicolumn{7}{|l|}{ Minimum tumour dose: } \\
\hline$<65 \mathrm{GyE}$ & 66 & $15 \cdot 5$ & 55 & $28 \cdot 1$ & 11 & $4 \cdot 8$ \\
\hline$>65$ to $<75 \mathrm{GyE}$ & 282 & $66 \cdot 2$ & 92 & 46.9 & 190 & $82 \cdot 6$ \\
\hline$>75 \mathrm{GyE}$ & 78 & $18 \cdot 3$ & 49 & $25 \cdot 0$ & 29 & $12 \cdot 6$ \\
\hline \multicolumn{7}{|l|}{ Best corrected visual acuity: } \\
\hline$\geqslant 6 / 6$ & 115 & $27 \cdot 0$ & 51 & $26 \cdot 0$ & 64 & $27 \cdot 8$ \\
\hline$>6 / 9$ to $<6 / 12$ & 187 & 43.9 & 88 & 44.9 & 99 & $43 \cdot 0$ \\
\hline$>6 / 15$ to $<6 / 24$ & 70 & $16 \cdot 4$ & 34 & $17 \cdot 3$ & 36 & $15 \cdot 7$ \\
\hline$>6 / 30$ to $<6 / 120$ & 37 & $8 \cdot 7$ & 17 & $8 \cdot 7$ & 20 & $8 \cdot 7$ \\
\hline \multirow{2}{*}{\multicolumn{7}{|c|}{ Length of visual acuity follow up (years): }} \\
\hline & & & & & & \\
\hline $0 \cdot 1$ to $<2$ & 102 & $23 \cdot 9$ & 31 & $15 \cdot 8$ & 71 & $30 \cdot 9$ \\
\hline$>2$ to $<4$ & 101 & $23 \cdot 7$ & 37 & 18.9 & 64 & $27 \cdot 8$ \\
\hline$>4$ to $<6$ & 70 & $16 \cdot 4$ & 22 & $11 \cdot 2$ & 48 & $20 \cdot 9$ \\
\hline$>6$ to $<8$ & 63 & $14 \cdot 8$ & 38 & $19 \cdot 4$ & 25 & 10.9 \\
\hline$>8$ & 90 & $21 \cdot 1$ & 68 & $34 \cdot 7$ & 22 & $9 \cdot 6$ \\
\hline \multicolumn{7}{|l|}{ Status follow up (years): } \\
\hline $0 \cdot 1$ to $<2$ & 65 & $15 \cdot 3$ & 7 & $3 \cdot 6$ & 58 & \\
\hline$>2$ to $<4$ & 87 & $20 \cdot 4$ & 31 & $15 \cdot 8$ & 56 & $24 \cdot 3$ \\
\hline$>4$ to $<6$ & 77 & $18 \cdot 1$ & 29 & $14 \cdot 8$ & 48 & $20 \cdot 9$ \\
\hline$>6$ to $<8$ & 64 & $15 \cdot 0$ & 31 & $15 \cdot 8$ & 33 & $14 \cdot 3$ \\
\hline$>8$ & 133 & $31 \cdot 2$ & 98 & $50 \cdot 0$ & 35 & $15 \cdot 2$ \\
\hline
\end{tabular}

All patients were examined and managed at the ocular oncology unit at the University of California, San Francisco. Patients had multiple observer, multi-modality examinations as previously described. ${ }^{13}$ If non-invasive tests were not diagnostic, a fine needle aspiration biopsy was used to confirm the diagnosis of a uveal melanoma. Before treatment all patients were characterised by age, best visual acuity, tumour location with respect to the optic nerve, fovea and equator, clinical tumour dimensions, and ultrasonographic measurement of tumour thickness. Vision was assessed in each eye by a technician using standard lighting and a Snellen chart. If the patient had less than $6 / 6$ acuity, automatic refraction was performed and the vision obtained with the Humphrey autorefractor (San Leandro, CA, USA).

Many patients were treated as part of a randomised, prospective study that compared ${ }^{125} \mathrm{I}$ brachytherapy with helium ion radiation. ${ }^{11}$ In all cases, informed consent was obtained. After treatment with either particle irradiation or ${ }^{125} \mathrm{I}$ plaques, patients were closely followed by us and their referral ophthalmologists. Patient and tumour characteristics of the 426 eligible patients are summarised in Table 2. Helium ions were used to treat 196 patients; 230 cases were treated with ${ }^{125} \mathrm{I}$ brachytherapy. The cohort had a mean age of $57 \cdot 2$ years. The majority $(54 \cdot 2 \%)$ of tumours were located posterior to the equator and $10.3 \%$ had some ciliary body involvement. The mean ultrasound tumour height was $5.0 \mathrm{~mm}$, and the mean largest tumour diameter was $10.8 \mathrm{~mm}$. The minimum tumour dose ranged from 48 GyE (Gray equivalents) to $80 \mathrm{GyE}$ with a mean dose of $70 \cdot 2 \mathrm{GyE}$. Before therapy $70.9 \%$ of patients had best corrected visual acuities of $\geqslant 6 / 12 ; 4.0 \%$ of patients had best corrected visual acuities $\leqslant 6 / 120$. The two treatment groups were not equivalent in several areas. Helium ion patients had longer follow up as this treatment was initiated 5 years before the ${ }^{125}$ I brachytherapy. Additionally, tumours treated with helium ion irradiation were, on average, significantly $(p<0.01)$ thicker than the plaque cases $(5.8 \mathrm{~mm}$ versus $5.2 \mathrm{~mm})$ and had a significantly $(p<0.05)$ greater percentage of cases with ciliary body involvement.

The mean length of time for treatment to last visual assessment was 5 years (median $4 \cdot 1$ (range $0 \cdot 1$ to $16 \cdot 3$ ) years). Limited follow up because of either enucleation or death was $31.2 \% ; 52$ cases were enucleated. The mean length of time from treatment to last patient contact was $6 \cdot 1$ years (median 5.6 (range 0.2 to $16 \cdot 4$ ) years).

Generally, patients were examined by us with clinical evaluation, ultrasonography and eye photography before and 3 months after treatment. Most patients were evaluated every 4 months during the first post-treatment year, 6 months the second year, 9 months the third year, then yearly after treatment. Some patients, primarily because of travel restrictions, were followed by local ophthalmologists. A total of 3015 post-treatment visual follow up measures were used for this study of which 
$76 \%$ were performed at UCSF. Mortality and metastatic information was obtained from family members, death certificates, tumour registries, and/or primary physicians. In the 52 cases enucleated after radiation, the visual acuities for these cases were classified as no light perception at the time of enucleation.

\section{STATISTICAL METHODS}

Statistical analyses were performed using semiparametric and non-parametric methods including Kaplan-Meier survival estimation techniques, Cox proportional hazards models, and log rank tests. ${ }^{14-16}$ Previous analyses had shown that the five factors associated with the rate of visual loss and the postoperative visual acuity were preoperative visual acuity, tumour thickness, tumour location with respect to the nerve and fovea, patient age, and the degree of retinal detachment at the time of treatment. ${ }^{8}$ These five factors were included in all analyses as first order effects. For each fitted Cox model, the relative risk (RR) was defined as an individual's estimated hazard relative to the median estimated hazard in the model cohort. Residual analyses were performed to suggest variable transformations, isolate influential observations, examine the proportional hazards assumption, and examine the interval censoring effect. ${ }^{17}$ The rate of visual loss was assessed using cumulative hazard plots. ${ }^{17}$ All statistical analyses and graphics were performed with S-Plus for Windows (Seattle, WA, USA: Statistical Sciences Inc, 1993) supplemented with macros written by the authors.

Our primary focus was to delineate subgroups of patients who retained good visual acuity or lost visual function; we modelled the visual acuity after irradiation using the time to a specific event with the Cox model. Three analyses were performed. To model the time to visual loss, we selected the time to visual acuity of half that at treatment (for example, if $6 / 15$ at treatment, the time until $6 / 30$ or worse was selected). This drop is equivalent to three lines on the Bailey-Lovie charts and represents a doubling of the minimal angle of resolution. Seventeen patients who presented with visual acuity worse than $6 / 120$ were excluded from these analyses. To model the retention of visual acuity, the time to visual acuity worse than $6 / 12$ was selected. Noting that visual acuity improvement after irradiation was rare, the analyses were restricted to the 302 patients with visual acuity of $6 / 12$ or better at the time of treatment. A third analysis to examine the length of useful visual function was also performed. For this analysis the time to visual acuity of $6 / 120$ or worse was selected for the 400 patients with pretreatment visual acuity better than 6/120. Problems as a result of transitory visual loss, interval censoring, dependent censoring, and loss of information by ignoring the actual visual acuity at the endpoint arose in all models.

Transitory visual loss was present in $16-23 \%$ of the cases depending on the model's visual threshold. The majority occurred within the first year after treatment reflecting a temporary post-treatment visual loss. Reasons for later onset transitory visual loss included post-radiation cataract followed by cataract extraction, clearing vitreous haemorrhage, resolving retinal detachment, or transitory macular oedema. To account for transitory visual loss, the follow up after the last visual loss threshold crossing was used as the endpoint. Patients with visual acuity better than the model threshold were not counted as visual losses. This technique is similar to the Markov models for transitory loss and simplified the computational analyses. ${ }^{18}$ The incidence of visual loss is slightly underestimated depending on the degree of censoring.

Interval censoring reflects that a patient had not reached an endpoint at one follow up but reached the endpoint by the time of the next follow up. In $80 \%$ of the patients the time between the last follow up before visual loss and the follow up with visual loss was under 1 year. Other analyses using the follow up before the visual loss or the interpolated date of visual loss suggested that ignoring the interval censoring did not dramatically affect the covariate conclusions as has been noted in other studies. ${ }^{19}$ The time to visual loss was slightly underestimated when visual loss occurred before the time of visual assessment.

Another problem in longitudinal data analysis occurs with dependent censoring when either cases censored by death were at higher risk of visual loss or when poor visual outcome cases are censored by follow up refusal before an endpoint was reached. ${ }^{20}$ For two analyses we used a low threshold for visual loss so that only $34 \%$ of cases were censored with less than $6 \%$ of the cases censored owing to death and the others censored owing to the time of analysis. The limited censoring and the majority of censoring, which were the result of the time of our study, suggested that the uninformative censoring assumption was reasonable in these analyses. The analysis for the time until visual acuity of $\leqslant 6 / 120$ led to greater censoring owing to death. As ciliary body involvement, larger tumour size, and older age were each predictors of visual loss and predictors of tumour or non-tumour related mortality, some dependent censoring was present.

\section{Results}

Patients who were followed for 3 years with eye retention or enucleated within 3 years were subgrouped into three visual outcome categories. Good visual outcome was defined as best corrected visual acuity of $6 / 12$ or better at any follow up at least 3 years after treatment. Poor visual outcome was defined as best corrected visual acuity of $6 / 120$ or worse at all follow ups after 3 years. The middle subgroup consisted of the remaining patients. The visual acuity at the time of treatment was predictive of the visual outcome (Table 3 ). While $42.0 \%$ of patients with preoperative visual acuity of $6 / 12$ or better led to good visual outcomes of $6 / 12$ or better after 3 years, only six of 62 patients with preoperative visual acuities between $6 / 15$ and $6 / 60$, and none of the 16 
Table 3 Three year post-treatment visual acuity as a function of pretreatment visual acuity

\begin{tabular}{lllllr}
\hline $\begin{array}{l}\text { Pre-treatment } \\
\text { visual acuity }\end{array}$ & $\geqslant 6 / 12$ & $6 / 15-6 / 120$ & $\leqslant 6 / 120$ & Enucleated & Total \\
\hline$\geqslant 6 / 12$ & $42 \%(95)^{\star}$ & $21 \%(48)$ & $26 \%(59)$ & $11 \%(24)$ & 226 \\
$6 / 15-6 / 60$ & $10 \%(6)$ & $19 \%(12)$ & $60 \%(37)$ & $11 \%(7)$ & 62 \\
$\leqslant 6 / 120$ & $0 \%(0)$ & $13 \%(2)$ & $88 \%(14)$ & $0 \%$ & 16 \\
Totals & $33 \%(101)$ & $20 \%(62)$ & $36 \%(110)$ & $10 \%(31)$ & 304 \\
\hline
\end{tabular}

*Percentage of patients within preoperative visual acuity group with 3 year visual acuity outcome (number of patients).

patients with preoperative visual acuities worse than $6 / 60$, had good visual outcomes. The majority of patients with poorer visual acuity at treatment had poor visual outcomes.

Table 4 summarises the Cox model for the time to visual loss of 3 or more Bailey-Lovie lines for patients with preoperative visual acuity of $\geqslant 6 / 120$. Ultrasound height was the dominant predictor of the rate of visual loss. Largest basal diameter was not predictive when height was included in the model. A clear trend in residual analyse ${ }^{17}$ suggested that a quadratic term was needed in addition to a linear term for the minimum distance to the nerve or fovea. This reflected that anterior located tumours have more rapid visual loss than those tumours in between the posterior pole and ciliary body. Older patients and eyes with larger amounts of retinal detachment at treatment had more rapid visual loss. Variables for preoperative visual acuity and treatment type did not significantly improve the fit.

The model was also fit within each treatment arm. There was a tendency for a more pronounced detrimental effect of tumour thickness on visual outcome in the iodine-125 plaque cases and a more pronounced effect of both posterior and anterior location in the helium ion cases. Minimum treatment dose was not contributory in any of the models suggesting that the doses given are above a visual retention threshold.

Kaplan-Meier time to onset curves for the

Table 4 Cox proportional hazards summary for time until $\geqslant 3$ line loss for the 409 patients with pre-treatment visual acuity of $\geqslant 6 / 120$

\begin{tabular}{|c|c|c|c|}
\hline Variable & $\begin{array}{l}\text { All cases } \\
(n=409)\end{array}$ & $\begin{array}{l}\text { Helium ion } \\
(n=190)\end{array}$ & $\begin{array}{l}I-125 \text { plaque } \\
(n=219)\end{array}$ \\
\hline Ultrasound height (mm) & $\begin{array}{l}1 \cdot 30^{\star} \\
1 \cdot 22-1 \cdot 40 \dagger \\
7 \cdot 48 \ddagger\end{array}$ & $\begin{array}{l}1 \cdot 27 \\
1 \cdot 16-1 \cdot 39 \\
5 \cdot 13\end{array}$ & $\begin{array}{l}1 \cdot 40 \\
1 \cdot 24-1 \cdot 57 \\
5 \cdot 60\end{array}$ \\
\hline Patient age (years) & $\begin{array}{l}1.02 \\
1.01-1.03 \\
4.85\end{array}$ & $\begin{array}{l}1 \cdot 02 \\
1 \cdot 01-1 \cdot 04 \\
3 \cdot 71\end{array}$ & $\begin{array}{l}1 \cdot 02 \\
1 \cdot 01-1 \cdot 04 \\
2 \cdot 65\end{array}$ \\
\hline Minimum to nerve or fovea (mm) & $\begin{array}{l}0.76 \\
0.68-0.85 \\
-4.85\end{array}$ & $\begin{array}{l}0.68 \\
0.57-0.81 \\
-4.33\end{array}$ & $\begin{array}{l}0.84 \\
0 \cdot 72-0.97 \\
-2 \cdot 31\end{array}$ \\
\hline Minimum to nerve or fovea $\left(\mathrm{mm}^{2}\right) \ddagger$ & $\begin{array}{l}1.02 \\
1.01-1 \cdot 02 \\
3 \cdot 23\end{array}$ & $\begin{array}{l}1.02 \\
1.01-1 \cdot 04 \\
2 \cdot 82\end{array}$ & $\begin{array}{l}1.01 \\
1.00-1.02 \\
1.67\end{array}$ \\
\hline $\begin{array}{l}\text { Ciliary body involvement } \\
\text { ( } 1 \text { if Yes, } 0 \text { if No) }\end{array}$ & $\begin{array}{l}1 \cdot 91 \\
1 \cdot 16-3 \cdot 17 \\
2 \cdot 52\end{array}$ & $\begin{array}{l}2 \cdot 46 \\
1 \cdot 32-4 \cdot 58 \\
2 \cdot 83\end{array}$ & $\begin{array}{l}1.30 \\
0.51-3.33 \\
0.55\end{array}$ \\
\hline Visual acuity at treatment $\left(\log _{2}\right)$ & $\begin{array}{l}1.04 \\
0.98-1 \cdot 11 \\
0.64\end{array}$ & $\begin{array}{l}1 \cdot 15 \\
0 \cdot 97-1 \cdot 38 \\
1.59\end{array}$ & $\begin{array}{l}0.92 \\
0 \cdot 76-1 \cdot 11 \\
-0.90\end{array}$ \\
\hline Degree of retinal detachment ( 0 to 5 ) & $\begin{array}{l}1 \cdot 14 \\
1 \cdot 02-1 \cdot 27 \\
2 \cdot 23\end{array}$ & $\begin{array}{l}1.15 \\
0.99-1.35 \\
1.83\end{array}$ & $\begin{array}{l}1 \cdot 11 \\
0.93-1.32 \\
1 \cdot 18\end{array}$ \\
\hline Treatment type ( 1 if ${ }^{125} \mathrm{I}, 0$ if $\mathrm{He}$ ) & $\begin{array}{l}0.82 \\
0.64-1.06 \\
-1.53\end{array}$ & & \\
\hline LR Stat $\$$ (dof) & $\begin{array}{r}126 \\
8\end{array}$ & $\begin{array}{c}66 \cdot 2 \\
7\end{array}$ & $\begin{array}{c}64 \cdot 8 \\
7\end{array}$ \\
\hline
\end{tabular}

*Cox model relative risk per unit scale change. + Ninety five per cent confidence interval for relative risk. $¥ Z$ statistic, absolute values of statistic greater than $1 \cdot 7,2 \cdot 3$, and $3 \cdot 1(2 \cdot 0,2 \cdot 6$, and 3.3 ) are equivalent to one sided (two sided) $p$ values of less than $0.05,0.01$, and 0.001 respectively. $§$ Likelihood ratio statistic, asymptotically $\chi^{2}$ distributed (degrees of freedom). two predominant visual acuity predictors (size and location) are given in Figure 1. Each group was stratified so that roughly half of the cases were in each stratum. The effect of both tumour size and tumour location was dramatic. Kaplan-Meier curves are also given for the stratified relative risk (RR) for three strata. While the 5 year rate of visual loss was $87 \cdot 6 \%$ for the lower stratum, it was $41 \cdot 0 \%$ for the higher stratum.

The rate of visual loss was analysed using cumulative hazard plots for the time to loss of three, six, and nine lines (Fig 2). These line losses are equivalent to a doubling, quadrupling, and octupling of the minimal angle of resolution. The plots were restricted to patients with preoperative visual acuities of $\geqslant 6 / 60$. The slopes of the cumulative hazard indicate the rate of visual loss. The visual loss rate is greatest immediately after treatment and decreases further about 4 years after treatment.

We assessed the rate of visual loss for patients who had maintained $\geqslant 6 / 12$ visual acuity for 3 years after treatment. Seventy three ( 35 helium ion patients and 38 iodine125 plaque patients) of the 101 patients who had maintained $6 / 12$ or better visual acuity at a follow up after 3 years had additional follow up. Of these 73 patients, 63 patients retained visual acuities of $6 / 24$ or better at their last visual examination (Fig 3 ). The reasons for the late onset visual loss in this cohort were late onset radiation retinopathy (five), enucleation (two), vitreous haemorrhage (two), and radiation cataract (one). The mean post-treatment follow up length of this cohort was $7 \cdot 0$ years. These results suggest that if good visual acuity is maintained for 3 to 4 years after treatment, there is a higher probability that it will be maintained for a longer time.

A visual acuity of $<6 / 12$ was selected to define the retention of good vision. A total of 119 of the 302 patients with pre-treatment acuity $\geqslant 6 / 12$ had not reached this visual endpoint as of last follow up. Cox model results are given in Table 5 and are similar to those for time to visual loss. The predominant predictors of visual retention were tumour thickness, tumour location (with respect to the nerve, fovea, and ciliary body), patient age, and the degree of subretinal detachment. Again there was a tendency for a more pronounced effect of tumour thickness in the iodine- 125 plaque cases and a more pronounced effect of tumour location with respect to the nerve and fovea or ciliary body in helium ion cases. Kaplan-Meier curves for the time to onset stratified by size, location, and relative risk are given in Figure 4. The 3 and 5 year rates of visual retention of patients with preoperative visual acuity of $\geqslant 6 / 12$ were $48 \cdot 2 \%$ and $36 \cdot 1 \%$ respectively.

An endpoint of $6 / 120$ or worse was selected to define the loss of visual function. A total of 192 of the 400 patients with pre-treatment acuity $\geqslant 6 / 60$ reached this visual endpoint. Cox model results are given in Table 6 . The predominant predictors of loss of visual function were tumour size, tumour location, and preoperative visual acuity. An age effect was present although it was not as predictive as it 

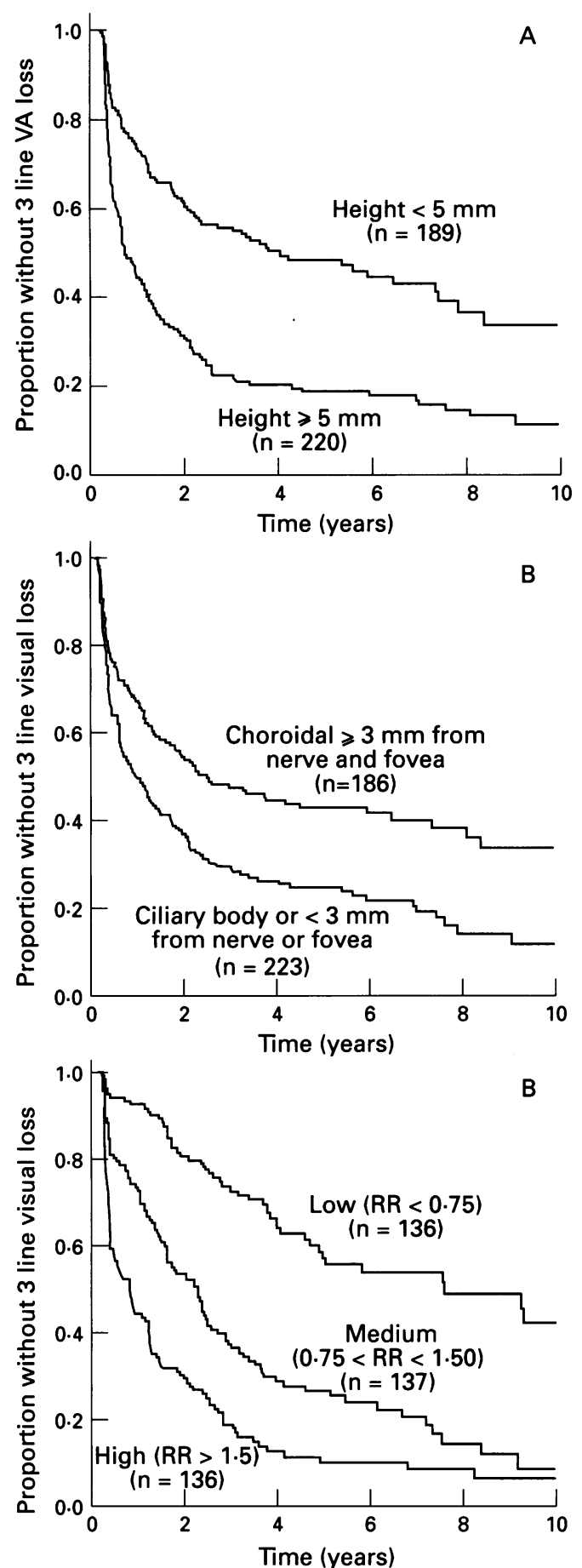

Figure 1 (A) Kaplan-Meier survival estimates for time until $\geqslant 3$ line loss for 409 patients with pre-treatment visual acuity $(V A)$ of $\geqslant 6 / 120$ stratified by $(A)$ pre-treatment ultrasound tumour height; $(B)$ pre-treatment tumour location with respect to the nerve, fovea, and ciliary body; (C) Cox model estimated relative risk.

was in models of visual retention. There was a tendency for a more pronounced effect of tumour thickness in the iodine- 125 plaque cases and a more pronounced effect of tumour location with respect to the nerve and fovea or ciliary body in helium ion cases. Kaplan-Meier curves to time to onset for stratified cases are given in Figure 5.

To examine possible correlations between the visual prognostic indicators and tumour related mortality, we stratified our patient cohort of 426 individuals into three categories. The strata were formed by splitting the 409 patients with visual acuity of $6 / 120$ or better at

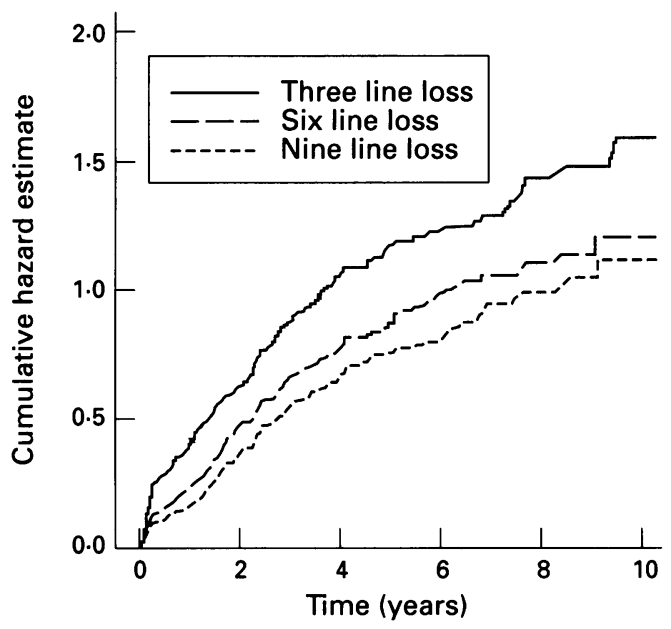

Figure 2 Nelson-Aalen cumulative hazard plots for time until $\geqslant 3, \geqslant 6$, and $\geqslant 9$ line loss for 384 patients with pre-treatment visual acuities of $\geqslant 6 / 60$. The slope of the cumulative hazard indicates the rate of visual loss. The most rapid rate of visual loss occurred immediately after treatment. A drop in the rate of visual loss was evident after 4 years.

treatment into thirds based on their relative risk (RR) of three line vision loss (Table 7).

Overall 54 of the 426 patients have developed detectable melanoma metastases. Kaplan-Meier survival curves are given for each of the three strata in Figure 6. A clear difference in metastatic rates was present (Mantel-Haenszel $\mathrm{p}<0.002$ ). Patients in the poor visual outcome group were at higher risk of early metastatic onset. Further follow up is needed to address the longer term metastatic rates.

\section{Discussion}

A significant number of patients with uveal melanoma will retain both an eye and good vision after irradiation. In this study $36.0 \%$ of patients retained $\geqslant 6 / 12$ visual acuities 3 or more years after radiation. Patients with preoperative visual acuities of $\geqslant 6 / 12$ maintained that level of vision 3 or more years after radiation in

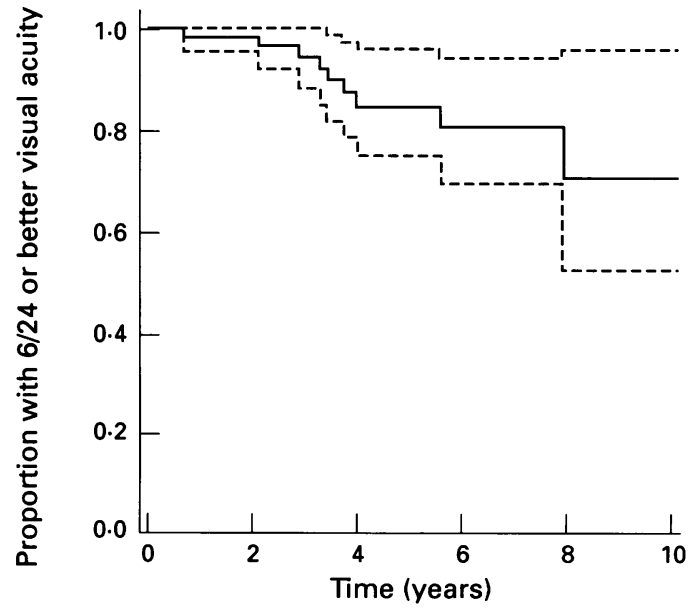

Figure 3 Kaplan-Meier survival estimates and 95\% confidence intervals for the time from first follow up after 3 years with visual acuity of $\geqslant 6 / 12$ to follow up with visual acuity of $\leqslant 6 / 24$. The mean time from treatment to post 3 year follow up for the 73 patients was 3.7 years. The time scale is from the post 3 year follow up and should be shifted $3 \cdot 7$ years to reflect time from treatment. 
Table 5 Cox proportional hazards summary for time until $<6 / 12$ for the 302 patients with pre-treatment visual acuity of $\geqslant 6 / 12$

\begin{tabular}{|c|c|c|c|}
\hline Variable & $\begin{array}{l}\text { All cases } \\
(n=302)\end{array}$ & $\begin{array}{l}\text { Helium ion } \\
(n=139)\end{array}$ & $\begin{array}{l}I-125 \text { plaque } \\
(n=163)\end{array}$ \\
\hline Ultrasound height (mm) & $\begin{array}{l}1 \cdot 39^{\star} \\
1 \cdot 28-1 \cdot 51 \dagger \\
7 \cdot 63 \ddagger\end{array}$ & $\begin{array}{l}1 \cdot 31 \\
1 \cdot 17-1 \cdot 47 \\
4 \cdot 67\end{array}$ & $\begin{array}{l}1 \cdot 60 \\
1 \cdot 39-1 \cdot 84 \\
6 \cdot 60\end{array}$ \\
\hline Patient age (years) & $\begin{array}{l}1.03 \\
1.02-1.05 \\
5.37\end{array}$ & $\begin{array}{l}1.03 \\
1.02-1.05 \\
3.63\end{array}$ & $\begin{array}{l}1 \cdot 03 \\
1.01-1 \cdot 05 \\
3 \cdot 23\end{array}$ \\
\hline Minimum to nerve or fovea (mm) & $\begin{array}{l}0.75 \\
0.65-0.87 \\
-3.91\end{array}$ & $\begin{array}{l}0.70 \\
0.56-0.87 \\
-3.23\end{array}$ & $\begin{array}{l}0.82 \\
0.68-1.00 \\
-1.98\end{array}$ \\
\hline Minimum to nerve or fovea $\left(\mathrm{mm}^{2}\right)$ & $\begin{array}{l}1.02 \\
1.00-1.03 \\
2.67\end{array}$ & $\begin{array}{l}1.02 \\
1.00-1 \cdot 04 \\
2.08\end{array}$ & $\begin{array}{l}1.01 \\
1.00-1.03 \\
1.59\end{array}$ \\
\hline $\begin{array}{l}\text { Ciliary body involvement } \\
(1 \text { if Yes, } 0 \text { if No) }\end{array}$ & $\begin{array}{l}1 \cdot 52 \\
0 \cdot 84-2 \cdot 76 \\
1 \cdot 37\end{array}$ & $\begin{array}{l}1.87 \\
0.88-3.96 \\
1.63\end{array}$ & $\begin{array}{l}0.90 \\
0.33-2 \cdot 50 \\
-0.19\end{array}$ \\
\hline Visual acuity at treatment $\left(\log _{2}\right)$ & $\begin{array}{l}0.69 \\
0.44-1.08 \\
-1.61\end{array}$ & $\begin{array}{l}0.81 \\
0.42-1.56 \\
-0.63\end{array}$ & $\begin{array}{l}0.65 \\
0.35-1.20 \\
-1.37\end{array}$ \\
\hline Degree of retinal detachment ( 0 to 5 ) & $\begin{array}{l}1 \cdot 14 \\
0.99-1 \cdot 33 \\
1 \cdot 79\end{array}$ & $\begin{array}{l}1.17 \\
0.95-1.44 \\
1.48\end{array}$ & $\begin{array}{l}1.07 \\
0.84-1 \cdot 37 \\
0.53\end{array}$ \\
\hline Treatment type ( 1 if ${ }^{125} \mathrm{I}, 0$ if $\mathrm{He}$ ) & $\begin{array}{l}0.80 \\
0.59-1.08 \\
-1.45\end{array}$ & & \\
\hline LR Stat\$ (dof) & $\begin{array}{r}120 \\
8\end{array}$ & $\begin{array}{c}55 \cdot 9 \\
7\end{array}$ & $\begin{array}{c}69 \cdot 3 \\
7\end{array}$ \\
\hline
\end{tabular}

*Cox model relative risk per unit scale change. $\nmid$ Ninety five per cent confidence interval for relative risk. $\ddagger Z$ statistic, absolute values of statistic greater than $1 \cdot 7,2 \cdot 3$, and $3 \cdot 1(2 \cdot 0,2 \cdot 6$, and relative risk. $\ddagger Z$ statistic, absolute values of statistic greater than $1 \cdot 7,2 \cdot 3$, and $3 \cdot 1(2 \cdot 0,2$
3.3 ) are equivalent to one sided (two sided) $p$ values of less than $0.05,0.01$, and 0.001 respectively. §Likelihood ratio statistic, asymptotically $\chi^{2}$ distributed (degrees of freedom).

$42 \%$ of cases. Other studies have demonstrated previously that treatment of tumours contiguous or involving the fovea or optic nerve have relatively poorer visual outcome. ${ }^{81221}$ In several multivariate analyses, tumour thickness, initial acuity, patient age, and type of radiation, in addition to tumour location, are important factors in visual outcome. ${ }^{810} 11$

Good visual acuity at 3 years after radiation was an excellent predictor of longer term visual prognosis. In those patients with $\geqslant 6 / 12$ acuities at over 3 years, 63/73 (86\%) were $\geqslant 6 / 24$ with a mean post-treatment follow up of 7.0 years. Undoubtedly, in older patients acuity will diminish further over time; however, as previously described with charged particles, the time frame chosen is such that it is unlikely that many of these eyes will be lost from neovascular glaucoma, although visually significant cataract continues to develop in approximately $8 \%$ per year of follow up. ${ }^{22}$

This study demonstrates that long term visual outcome can be predicted based on the preoperative visual acuity, the tumour location with respect to the optic nerve and fovea and ciliary body, the tumour thickness, and the patient age. For example, 57 of the $74(77 \%)$ patients with choroidal tumours thinner than $4.5 \mathrm{~mm}$ and located at least $3 \mathrm{~mm}$ from the nerve and fovea had kept their preoperative visual acuity of $6 / 12$ or better at a mean follow up of 6.5 years. This percentage was higher in the younger patients. The lower metastatic rate within this group will contribute less information (for example, number of metastatic cases) than the poorer visual outcome group in the comparison of treatments. Entering patients in this subgroup into the COMS trial should be given careful consideration. ${ }^{23}$

Tumour related mortality was lower in patients who retained good vision as compared with those who did not. The poor prognosis visual outcome group had a significantly higher
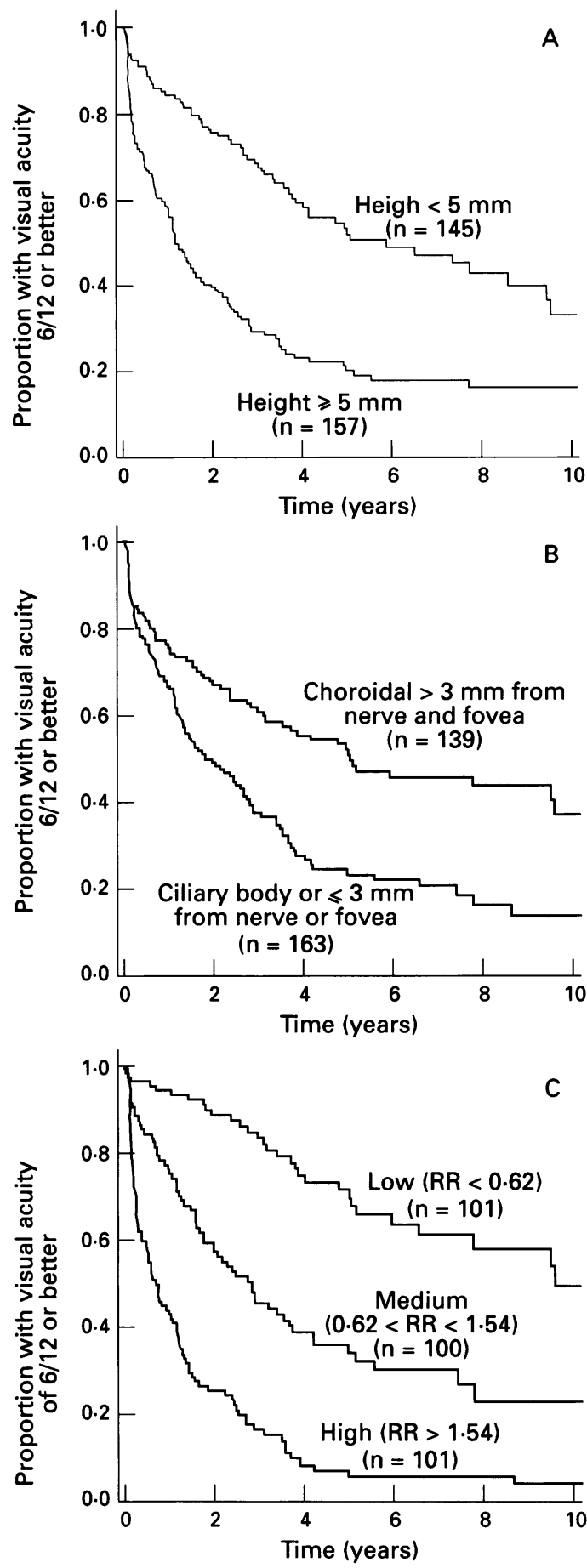

Figure 4 Kaplan-Meier survival estimates for time until $<6 / 12$ for 302 patients with pre-treatment visual acuity of $\geqslant 6 / 12$ stratified by $(A)$ pre-treatment ultrasound tumour height; (B) pre-treatment tumour location with respect to the nerve, fovea, and ciliary body; (C) Cox model estimated relative risk.

risk of metastatic onset. There were two contributing factors. The poor vision group was most dependent on tumour height, and these thicker tumours have larger diameters, a known prognostic indicator for metastatic risk. The poor vision group also contained 26 of the 44 tumours involving the ciliary body, another known metastatic risk indicator. Both the good and medium visual prognostic groups had 5 year metastatic estimates under $10 \%$.

No significant treatment differences between helium ion irradiation and 125I brachytherapy visual outcomes were found after Cox model covariate adjustments. Some 
Table 6 Cox proportional hazards summary for time until $\geqslant 6 / 120$ for the 400 patients with pre-treatment visual acuity of $>6 / 120$

\begin{tabular}{|c|c|c|c|}
\hline Variable & $\begin{array}{l}\text { All cases } \\
(n=400)\end{array}$ & $\begin{array}{l}\text { Helium ion } \\
(n=186)\end{array}$ & $\begin{array}{l}\text { I-125 plaque } \\
(n=214)\end{array}$ \\
\hline Ultrasound height (mm) & $\begin{array}{l}1 \cdot 34^{\star} \\
1 \cdot 23-1 \cdot 45 \dagger \\
7 \cdot 00 \ddagger\end{array}$ & $\begin{array}{l}1 \cdot 32 \\
1 \cdot 18-1 \cdot 47 \\
5 \cdot 01\end{array}$ & $\begin{array}{l}1 \cdot 43 \\
1 \cdot 25-1 \cdot 64 \\
5 \cdot 20\end{array}$ \\
\hline Patient age (years) & $\begin{array}{l}1.02 \\
1.01-1.03 \\
3.19\end{array}$ & $\begin{array}{l}1.02 \\
1.00-1 \cdot 03 \\
2 \cdot 08\end{array}$ & $\begin{array}{l}1.02 \\
1 \cdot 00-1 \cdot 04 \\
2 \cdot 40\end{array}$ \\
\hline Minimum to nerve or fovea (mm) & $\begin{array}{l}0.75 \\
0.66-0.85 \\
-4 \cdot 40\end{array}$ & $\begin{array}{l}0.71 \\
0.59-0.87 \\
-3.41\end{array}$ & $\begin{array}{l}0.80 \\
0.67-0.96 \\
-2.36\end{array}$ \\
\hline Minimum to nerve or fovea $\left(\mathrm{mm}^{2}\right)$ & $\begin{array}{l}1.02 \\
1.01-1.02 \\
2 \cdot 89\end{array}$ & $\begin{array}{l}1.01 \\
1.00-1.03 \\
1.51\end{array}$ & $\begin{array}{l}1 \cdot 02 \\
1 \cdot 00-1 \cdot 03 \\
2 \cdot 17\end{array}$ \\
\hline $\begin{array}{l}\text { Ciliary body involvement } \\
\text { ( } 1 \text { if Yes, } 0 \text { if No) }\end{array}$ & $\begin{array}{l}1.84 \\
0.98-3.46 \\
1.91\end{array}$ & $\begin{array}{l}2 \cdot 56 \\
1 \cdot 17-5 \cdot 57 \\
2 \cdot 36\end{array}$ & $\begin{array}{l}1 \cdot 17 \\
0 \cdot 38-3 \cdot 59 \\
0 \cdot 28\end{array}$ \\
\hline Visual acuity at treatment $\left(\log _{2}\right)$ & $\begin{array}{l}0.77 \\
0.66-0.89 \\
-3.40\end{array}$ & $\begin{array}{l}0.84 \\
0.68-1.04 \\
-1.64\end{array}$ & $\begin{array}{l}0 \cdot 71 \\
0.56-0.90 \\
-2 \cdot 77\end{array}$ \\
\hline Degree of retinal detachment ( 0 to 5 ) & $\begin{array}{l}1 \cdot 01 \\
0 \cdot 89-1 \cdot 16 \\
0 \cdot 19\end{array}$ & $\begin{array}{l}1 \cdot 05 \\
0 \cdot 88-1 \cdot 25 \\
0 \cdot 50\end{array}$ & $\begin{array}{l}1 \cdot 03 \\
0 \cdot 83-1 \cdot 28 \\
0 \cdot 27\end{array}$ \\
\hline Treatment type ( 1 if ${ }^{125} \mathrm{I}, 0$ if $\mathrm{He}$ ) & $\begin{array}{l}1.01 \\
0.74-1.37 \\
0.04\end{array}$ & & \\
\hline LR Stat\$ (dof) & $\begin{array}{r}120 \\
8\end{array}$ & $\begin{array}{c}70 \cdot 1 \\
7\end{array}$ & $\begin{array}{c}58 \cdot 5 \\
7\end{array}$ \\
\hline
\end{tabular}

*Cox model relative risk per unit scale change. + Ninety five per cent confidence interval for relative risk. $¥ Z$ statistic, absolute values of statistic greater than $1 \cdot 7,2 \cdot 3$, and $3 \cdot 1(2 \cdot 0,2 \cdot 6$, and 3.3 ) are equivalent to one sided (two sided) $p$ values of less than $0.05,0.01$, and 0.001 respectively. $§$ Likelihood ratio statistic, asymptotically $\chi^{2}$ distributed (degrees of freedom).

differences of covariate effects within individual treatments were evident. Although these differences did not reach statistical significance (reflective of the lower power to detect treatment interactions), they were consistent across all analyses. Larger posterior and anterior location effects were present with helium ion irradiation. This may reflect the larger doses to the nerve and fovea with the greater marginal doses of this treatment. More rapid visual losses in anterior tumours may be related to the higher doses and greater inclusion of anterior segment structures in the irradiation port. The increased risk of neovascular glaucoma with helium ion irradiation suggests this effect although we have noted that visual loss almost always precedes the onset of detectable rubeosis and glaucoma. Larger tumour size effects were present with brachytherapy. This may reflect the increased overall radiation area with plaques. The longer term visual acuity outcomes suggest that late onset visual loss may be greater with brachytherapy than with helium irradiation although further follow up will be needed to better address this issue.

In this study the overall actuarial rate of metastases was $6.4 \%$ at 3 years and $13.3 \%$ at 5 years. Our data, along with previous analysis, show similar survival with irradiation or enucleation. This issue may be better addressed by the COMS outcomes, although the significantly higher tumour control problems with plaque therapy than with helium ion therapy may complicate the conclusions. ${ }^{11}$ In this study 27 tumours had local radiation failures. Twenty of these were following ${ }^{125} \mathrm{I}$ brachytherapy and seven were following helium ion irradiation. Nine patients developed detectable metastases after the local recurrence.

We have delineated a subgroup with high probability of visual retention. In this patient group it appears to us that retention of the eye is useful and can often be accomplished with
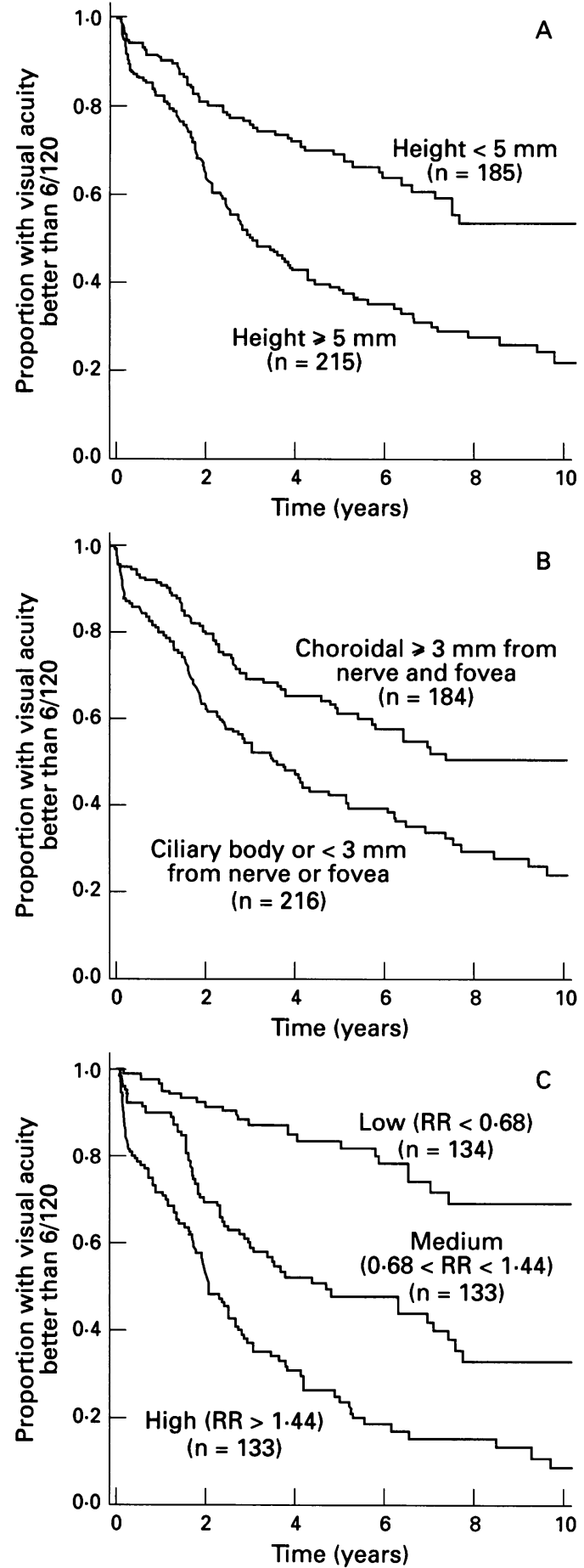

Figure 5 Kaplan-Meier survival estimates for time until $\leqslant 6 / 120$ for 400 patients with pre-treatment visual acuity of $>6 / 120$ stratified by $(A)$ pre-treatment ultrasound tumour height; (B) pre-treatment tumour location with respect to the nerve, fovea and ciliary body; (C) Cox model estimated relative risk.

retention of good visual function. We also delineated another subgroup with low probability of retaining useful visual function. For this group the benefit of eye retention and cosmesis versus the need for clinical follow up and the incidence of radiation complications or failures need to be considered.

Several issues are not.addressed by this study. While we attempted to match our patients to those in another study, differences in patient populations that we could not anticipate may have had an effect on our results. We included some patients who did not meet non-ocular COMS criteria since we 
Table 7 The 5 year metastatic rates for each stratum and overall

\begin{tabular}{lcc}
\hline Stratum & No & 5 Year metastatic rate $(S E)$ \\
\hline Good $(\mathrm{PI}<1 \cdot 85)$ & 136 & $6 \cdot 4 \%(2 \cdot 5 \%)$ \\
Medium $(1 \cdot 85<\mathrm{PI}<2 \cdot 5)$ & 137 & $9 \cdot 3 \%(3 \cdot 0 \%)$ \\
Poor $(\mathrm{PI}>2 \cdot 5)$ & 136 & $23 \cdot 0 \%(3 \cdot 7 \%)$ \\
Overall & 426 & $13 \cdot 3 \%(1 \cdot 9 \%)$ \\
\hline
\end{tabular}

$\mathrm{PI}=$ prognostic indicator.

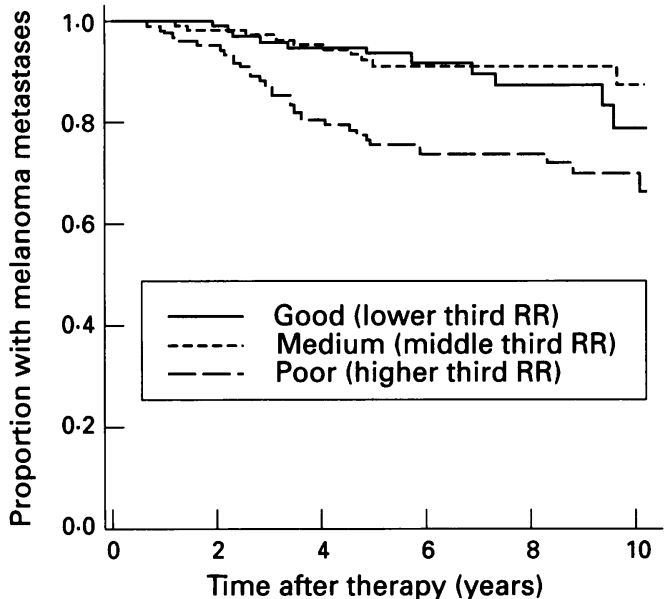

Figure 6 Kaplan-Meier survival estimates for time until metastatic detection for 409 patients with pre-treatment visual acuity of $\geqslant 6 / 120$ stratified by Cox model estimated relative risk.

were unsure how to determine which patients had compromised non-tumour related survival. COMS employed these exclusions as the primary endpoint for its trial was patient death and not tumour related death. It is doubtful that these non-ocular exclusions would affect our results. Since we have routinely treated tumours contiguous to the optic nerve with radiation, we doubt whether our visual result data were biased in favour of either brachytherapy or charged particle radiation. Similarly, we are following more than 400 indeterminant pigmented choroidal tumours that probably would have been treated in some centres. ${ }^{24}$ Since these tumours are relatively small, it is likely that if they were treated by us, our visual results would have been even better. Two recent studies have assessed visual performance of patients who were treated with either enucleation or radiation. In both studies the majority of patients did well after either therapy; however, probably because of age, only about two thirds were working at the time of treatment. ${ }^{25} 26$ It is uncertain, therefore, what level of retained bilateral visual acuity in a normal working individual confers a definite advantage compared with an enucleated patient.

Supported in part by Research to Prevent Blindness and That Man May See.
1 Seddon JM, Gragoudas ES, Albert DM, Hsieh CC, Polyvogianis L, Friedenberg GR. Comparison of surviva rates for patients with uveal melanoma after treatment with proton beam irradiation or enucleation. $A m \mathcal{F}$ Ophthalmol 1995; 99: 282-90.

2 Lommatzsch PK. Results after beta-irradiation $(106 \mathrm{Ru} / 106 \mathrm{Rh})$ of choroidal melanomas: 20 years' experience. Br $\mathcal{F}$ Ophthalmol 1986; 70: 844-51.

3 Augsburger J, Gamel JW, Sardi VF, Greenberg RA, Shields JA, Brady LW. Enucleation vs cobalt plaque radiotherapy for malignant melanomas of the choroid and ciliary body. Arch Ophthalmol 1986; 104: 655-61.

4 Gragoudas ES, Seddon JM, Egan K, Glynn R, Munzenrider $\mathrm{J}$, Austin-Seymour $\mathrm{M}$, et al. Long-term results of proton beam irradiated uveal melanomas. Ophthalmology 1987; 94: 349-53.

5 Adams KS, Abramson DH, Ellsworth RM, Haik BG, Bedford M, Packer S, et al. Cobalt plaque versus enucleation for uveal melanoma: comparison of survival rates. Br f Ophthalmol 1988; 72: 494-7.

6 DePotter P, Shields CL, Shields JA, Cater JM, Tardis DJ. Impact of enucleation versus plaque radiotherapy in the management of juxtapapillary choroidal melanoma on management of juxtapapillary choroidal melanom

7 COMS. Design and methods of a clinical trial for a rare condition: the collaborative ocular melanoma study Controlled Clinical Trials 1993; 14: 362-91.

8 Char DH, Castro JR, Kroll SM, Irvine AR, Quivey JM, Stone RD. Five year follow-up of helium ion therapy for uveal melanoma. Arch Ophthalmol 1990; 108: 209-14.

9 Shields JA, Gragoudas ES, Char DH. Comments on management of uveal melanomas: a continuing dilemma. Cancer 1994; 74: 3074-5.

10 Seddon IM, Gragoudas ES, Polivogianis L, Hsieh CC Egan $\mathrm{K}$, Goitein $\mathrm{M}$, et al. Visual outcome after proton beam irradiation of uveal melanoma. Ophthalmology 1986 ; 93: $666-74$.

11 Char DH, Quivey JM, Castro J, Kroll S, Phillips T. Helium ions versus iodine 125 brachytherapy in the management of uveal melanoma: a prospective randomized, dynamically balanced trial. Ophthalmology 1993; 100: 1547-54.

12 Cruess AF, Augsburger JJ, Shields JA, Donoso L, Amsel J. Visual results following cobalt plaque radiotherapy for posterior uveal melanomas. Ophthalmology 1984; 91: posterior

13 Char DH, Stone RD, Irvine AR, Crawford JB, Hilton GF Schwartz A Diagnostic modalities in choroidal Schwartz A. Diagnostic modalities in
melanoma. Am Ophthalmol 1980; 89: 223-30.

14 Kaplan EL, Meier P. Nonparametric estimation from incomplete observations. F Am Stat Assoc 1958; 53: 457-81.

15 Cox DR. Regression models and life tables (with discussion). $\mathcal{F} R$ Stat Soc $B$ 1972; 34: 187-220.

16 Kalbfleisch J, Prentice RL. The statistical analysis of failure time data. New York: Wiley, 1980.

17 Andersen PK, Borgan O, Gill RD, Keiding N. Statistical models based on counting processes. New York: SpringerVerlag, 1993.

18 Hill A, Maguire M, Hawkins BS, Newhouse MM. The Markov process as a general method for nonparametric analysis of right-censored medical data. 7 Chron Dis 1986 ; 39: $595-604$.

19 Samuelsen SO, Kongerud J. Interval censoring in longitudinal data of respiratory symptoms in aluminum potroom workers: a comparison of methods. Stat Med 1994 13: $1771-80$.

20 Caplan RJ, Pajak TF, Cox JD. Analysis of the probability and risk of cause-specific failure. Int $\mathcal{F}$ Rad Onc Biol Phys 1994; 29: 1183-6.

21 Young LH, Gragoudas ES. Macular uveal melanoma treated with proton beam irradiation. 10-year follow-up treated with proton beam irradiation. 10-year follow-up 14: 43-6.

22 Meecham WJ, Char DH, Kroll SM, Collier M, Castro JR. Anterior segment complications after helium ion radiation therapy for uveal melanoma. Radiation cataract. Arch Ophthalmol 1994; 112: 197-203.

23 Fine SL. Do I take the eye out or leave it in? Arch Ophthalmol 1986; 104: 653-4.

24 Butler P, Char DH, Zarbin M, Kroll S. Natural history of indeterminant pigmented Ophthalmology 1994; 101: 710-6.

25 Augsburger JJ, Goel SD. Visual function following enucleation or episcleral plaque radiotherapy for posterior uveal ation or episcleral plaque radiotherapy for post
melanoma. Arch Ophthalmol 1994; 112: 786-9.

26 Edwards MG, Schachat AP. Impact of enucleation for choroidal melanoma on the performance of visiondependent activities. Arch Ophthalmol 1991; 109: 519-21. 